\title{
Circuit
}

Musiques contemporaines

\section{L’illustration du numéro}

\section{Danielle Péret}

Volume 6, numéro 1, 1995

Tremblay/Varèse/Messiaen : Gilles Tremblay analyste

URI : https://id.erudit.org/iderudit/902124ar

DOI : https://doi.org/10.7202/902124ar

Aller au sommaire du numéro

Éditeur(s)

Les Presses de l'Université de Montréal

ISSN

1183-1693 (imprimé)

1488-9692 (numérique)

Découvrir la revue

Citer ce document

(1995). L’illustration du numéro : Danielle Péret. Circuit, 6(1), 81-82.

https://doi.org/10.7202/902124ar

Ce document est protégé par la loi sur le droit d'auteur. L'utilisation des services d'Érudit (y compris la reproduction) est assujettie à sa politique d'utilisation que vous pouvez consulter en ligne.

https://apropos.erudit.org/fr/usagers/politique-dutilisation/
Cet article est diffusé et préservé par Érudit.

Érudit est un consortium interuniversitaire sans but lucratif composé de l’Université de Montréal, l'Université Laval et l'Université du Québec à Montréal. Il a pour mission la promotion et la valorisation de la recherche. https://www.erudit.org/fr/ 


\section{L'ILLUSTRATION DU NUMÉRO}

\section{DANIELLE PÉRET}

Danielle Péret est née à la frontière de la France et de l'Alsace en 1944. Après des humanités jurassiennes, elle est allée étudier de l'autre côté de la frontière, la photographie à Vevey, le graphisme à Bâle. Elle a travaillé sur l'architecture rurale au Musée des arts et traditions populaires à Paris et a photographié le patrimoine québécois à son arrivée au Québec en 1977. Elle a fréquenté les marges de la littérature en illustrant des auteurs de la N.B.J. et de la revue Imagine pendant les années 1980. Un autre passage de frontière l'a amenée dans le monde virtuel; elle fait maintenant de la mise en pages ef de l'illustration sur ordinateur.

\section{LES CEUVRES}

"D'une formation marquée par le Bauhaus, j'ai gardé la jubilation de la combinatoire graphique. Pour qui manipule les images, la tentation de l'abstraction finit toujours par surgir, elle est revenue au détour d'une recherche photographique pour la revue CIRCUIT. La démarche créatrice de Gilles Tremblay, passant de la graphie des écorces de bouleaux au monde des sons, m'a renvoyée à mes anciennes surprises de laboratoire lorsque les hasards de la chimie photographique volontairement malmenée faisaient apparaître, à partir d'éléments figuratifs, des mondes cachés. Avec l'ordinateur, la rapidité d'opération est plus grande mais inversement proportionnelle aux possibilités de surprise. II a fallu redévelopper avec la machine la trituration joyeuse du hasard. „

Danielle Péret 


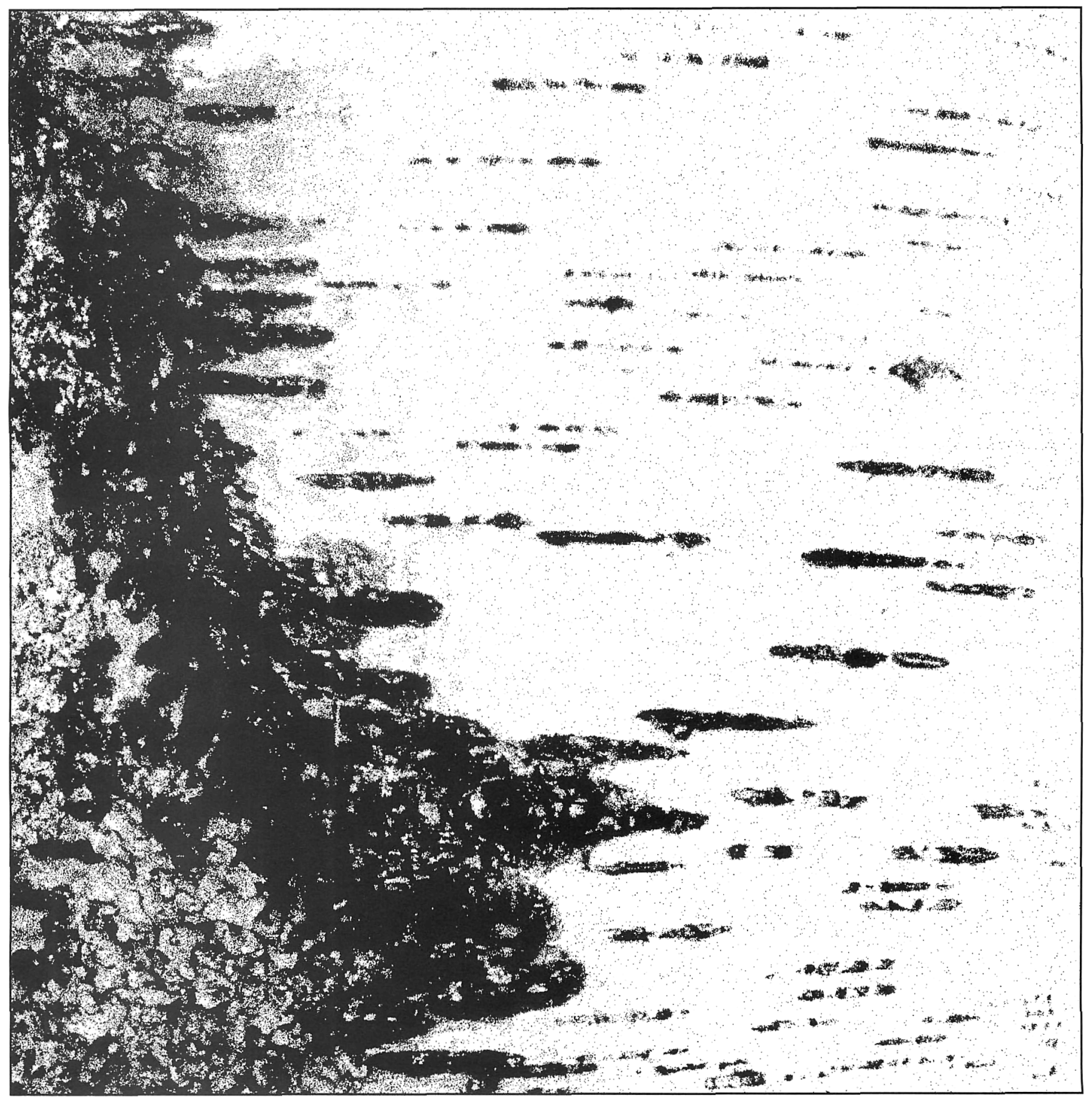

